line joining any two particles of air shall always be parallel to its original direction, an assumption which is manifestly incorrect. If I rightly understand the description of $\mathrm{Mr}$. Wilson's integrator on p. 467 , the trace given by it is precisely that which has just been shown in the case of my own machine to be based on a fallacious assumption. But though the trace may be useless, the summation of the movements of the table above described gives results which are representative of physical realities, being in fact the quadrantal components. of the wind-movement at the station during the period dealt with by the machine. I trust that the preceding remarks will suffice to justify the statements contained in my last letter. Dr. von Oettingen's remark, referred to in my concluding sentence, related, not to his wind-component-integrator, but to the continual change of form in what may be called the physical Lambert's line, and implied the consequent advisability of discarding Lambert's method of treatment.

Charles E. BuRTON

$3^{8}$, Barclay Road, Walham Green, S.W., October 14

P.S, - On September 2 I last I forwarded to Prof. Stokes a de scription, with drawings, of two forms of wind-component in tegrator, suitable either for attachment to a cup and vane anemometer, or for the reduction of existing anemograms of the pattern adopted by the Meteorological Office ; and of simpler mechanism than my earlier machine, or Dr. von Oettingen's.

\section{Calabar Bean as a Preservative}

As many find such a difficulty in preserving entomological and other natural history specimens it may not be uninteresting to your readers to have a brief note on the use of Calabar Bean as a preservative. About eight years ago, when Aquilla Smith, M.D., Professor of Materia Medica, Trinity College, Dublin, was showing me through the museum that he has rendered so famous, I was struck by the perfect manner in which the specimens were preserved; the little brown beetle that is generally such a pest in similar collections being entirely absent. Dr. Smith told me that he treated the specimens with tincture of Calabar Bean, and very kindly gave me a bottle of the tincture. I used the tincture freely in my cabinet of Lepidoptera, and, although the collection has been wofully neglected since, it has remained quite free from mites. Dr. Smith tells me that the tincture was prepared by Mr. Squire of 277 , Oxford Street, London, its strength being one part of the bean to eight of (rectified?) spirit. I might mention that Mr. Fetherstonhaugh used some of the tincture which I gave him in his cabinet, and was delighted with its action. $\AA$ drop of the tincture is placed on the body of the insect. I found it a good plan to do this whilst the insect was on the drying board, as otherwise, in newly set insects, the damping with spirit caused the wings to spring.

$$
\text { E. MacDowel Cosgrave }
$$

\section{A Correction}

I FIND that the term "glissette" is not used precisely in the sense which I had supposed. A reference to Mr. Besant's "Notes on Roulettes and Glissettes" (which I had not before me last week) shows that the envelopes of the moving lines, to which the theorem in my last letter refers, would be properly described as roulettes. It is obvious, however, that glissettes are in general also roulettes.

Royal Indian Engineering College.

\section{Effect of Green in Painted Windows}

I NOTICED to-day a curious effect in the east windows of Old Upton Church which may interest artists among your readers, and of which I should be glad to see any explanation. The pattern is in small regular pieces in which a strong red is prevalent, especially in the ribbon round the edge. Green is perhaps the least represented in area. At all events, generally, red largely prevails over green. The latter is not over brilliant. At a distance of ten feet the general effect is red. At that distance I see the pattern sharply, and green is not at all obtrusive. At the length of the church, say fifty feet off, I cannot distinguish the pattern, and the whole window looks a thin watery green haze; the bright red margin is inappreciable.

Richmond, October 12
THE AUTUMN MEETING OF THE IRON AND STEEL INSTITUTE

$A^{T}$ the meeting of the above Institution, which has just taken place, several papers of scientific and practical interest were read and discussed. They may be broadly divided into two classes, viz. Ist, those relating to the production of iron and steel, from the ore, and the qualities of the material when produced; and and, the various applications to which steel has been put in recent times. . The latter class of papers, at the recent meeting, dealt principally with the use of steel in the manufacture of ordnance, small arms, projectiles, and gun-carriages, and the papers, some of which were of great interest, will be reserved for consideration in a separate notice. Amongst the papers dealing with the manufacture of steel we may notice specially a memoir by Herr Paul Kupelweiser of Witkowitz, in Austria, on recent progress attained in the use of the basic process at the works with which he is connected. This process, which has been frequently referred to in NATURE, seems-probably on account of the quality of the ores met with-to have been adopted more frequently in Continental steel works than in our own country, for according to Herr Kupelweiser's summary, no less than thirty works in France, Belgium, Germany, Austria, and Russia, bave acquired licences under the Thomas patents, the greater number of these being already at work; while the remainder are adapting their old plant, or erecting new works with the view to its immediate introduction. The weak point of the process hitherto has undoubtedly been the want of durability in the refractory linings of the converters, and on this point the author states that, in spite of numerous trials with other materials, the works with which he is acquainted still use the materials originally proposed by $\mathrm{Mr}$. Thomas, viz. either the basic bricks or the shrunk lime and tar mixture. At Witkowitz, however, a new material has been used containing a comparatively small percentage of silica, and the quality of the bricks manufactured from this has been found to be materially improved. Ground brick mixed with 5 to ro per cent. of tar is also used at many works for lining as well as for repairs. Basic tuyères have been tried in many places, but are not commonly used; but the author states that magnesia obtained by precipitation from chloride of magnesia by milk of lime appears, from experiments made on a small scale, to be a promising material for making tuyères. As regards the quality of the steel he makes the following remarkable statement:- "The basic process, as regards the quality of its products, is not only completely equal to the acid process, but even, in my opinion, superior to the latter." As a specimen of the excellent quality of the mild steel manufactured at Witkowitz the author exhibited a locomotive boiler tube made of this material, which had been expanded cold by neans of a tube expander from 9 to 17 millimetres, on an original diameter of 48 millimetres, equal to an extension of from 20 to 36 per cent. on the periphery of the material, without even splitting at the line of weld.

Another paper of great interest to foreign manufacturers was Prof. Tünner's memoir "On the Use of Lignite or Brown Coal in the Blast Furnace." It is well known that the Austro-Hungarian Empire contains immense deposits of this fuel. It would be difficult to over-estimate the benefit which would accrue to the iron industry of Austria if this abundant and inexpensive fuel could be used successfully in the blast-furnace. All the experiments made in this direction till last year were of a more or less isolated and unsatisfactory character. In June, I880, however, the "Mining and Metallurgical Association of Styria and Carintbia "appointed a committee to investigate the subject afresh. This committee has not yet reported, or indeed concluded its labours, but it is satisfactory to learn that it is fully acknowledged that there is no theoretical difficulty in the way of smelting 
iron with raw or coked brown coal, and that the practical difficulties have been partly solved; for we learn that at Kalan a blast-furnace was for a time worked with a mixture of from 25 to 75 per cent. of brown coal, and 25 to 75 per cent. of co'ze. The great difficulty in the utilisation of this fuel lies in the fact that, owing to the high percentage of contained water, the raw coal is liable, when heated, to splinter up into small pieces, somewhat similarly to anthracite, and the colve formed of it is also very small and tender. It is, however, satisfactory to learn from Prof. Tünner that these difficulties may be in a measure obviated by the use of a strong blast, and especially constructed furnaces. The chief difficulty arises in continuing the operation when sponge-iron is produced; but it is suggested that the reduction might be completed from this stage in a small furnace, such as a Siemens furnace with co'sed fuel.

The results of the further labours of the Committee will be awaited with great interest.

Mr. G. J. Snelus of Workington contributes a paper on the Distribution of the Elements in Steel Ingots. It was till quite lately taken for granted that the steel plates, \&c., produced from ingots were not only mechanically, but chemically homogeneous. When the disastrous failure of the boiler plates of the Livadia took place, this subject, amongst many others, was minutely investigated, and samples of different portions of the plates were subnitted to chemical analysis, with the startling result that the proportion; of carbon, manganese, phosphorus, and sulphur were found to vary greatly. At the spring meeting of the Institute Mr. Stubbs announced, during a discussion, that he had discovered that during the solidification of the ingots a redistribution of the elements took place, the carbon, sulphur, and phosphorus going to that part which remained fluid the lon rest. Mr. Snelus has now by experiment confirmed this statement so far as large ingots are concerned. This fact is brought out most clearly in the following table, which gives the analysis of carbon, sulphur, and phosphorus, of six samples taken from a slice $2 \mathrm{I}$ inches below the top of an ingot, measuring 7 feet $\times 19^{\prime \prime} \times 19^{\prime \prime}$, and a similar number from a slice 4 inches above the bottom; the number in each case being taken fron the outside, number 6 from the centre, and the remaining numbers from intermediate positions:-

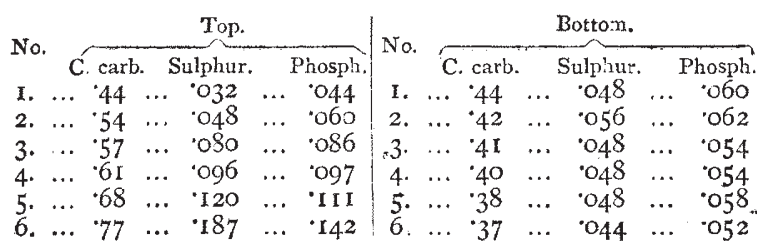

In examining smaller ingots, however, Mr. Snelus found that the metal was practically homogeneous, and consequently the want of uniformity in the Livadia's boiler plates cannot be accounted for in this way, seeing that they were produced from relatively small ingots.

Mr. Elward Richards gave an account of a series of experiments on the strength of samples of mild steel. The specimens were tested both for ordinary tensile strength, and also for the tensile strength after the samples had been submitted to long-continued tensile and compressive strains approaching the elastic limit to torsional strains, and to long-continued strains below the elastic limit. He also made experiments on the strength of samples of plates which had been perforated. The results are of great interest, and will well repay careful study, though they are too voluminous to be reprinted here. We may however notice that in one sense these experiments go to support the much-combated opinion held by Dr. Siemens, that any mechanical treatment to which mild steel is subjected, has invariably the effect of increase of strength.

\section{THE "QUARTERLY REVIEW" ON EARTHQUAKES}

THE pages of the Quarterly Review constitute perhaps the very last place in which one would look for a new theory on an important scientitic question, and the perusal of an article in the July number of that journal on "Earthquakes : their Cause and Origin," has left us in grave doubt as to whether the author of it is writing seriously or is perpetrating a gigantic practical joke.

The article professes to be a review of the well-known and valuable works of Schmidt, Heim, and Mallet on Earthquakes; but added to this list of books for review we have "Scepticism in Geology, and the Reasons for it, by Verifier"! When we find that a considerable portion of the article is occupied with passages quoted from this last-mentioned book, in which the most absurd misconceptions and misconstructions of the writings of Lyell, Darwin, Huxley, and others are embodied, we can scarcely forbear from leaving the task of framing an hypothesis concerning earthquakes, in order to indulge in conjectures as to the relations which may possibly exist between "Verifier" and the author of the article in question.

Ignoring the whole body of facts which have been accumulated by seismologists concerning the amplitude, direction, and velocity of earthquake-waves, the author denies that the earthquake movements are waves at all; and in his reasoning (if such it can be called) he hopelessly confuses the vibration with the shock which has produced it. Dismissing with contempt the views of others on the subject, he proceeds to offer his own conjecture as to the cause of earthquakes. It is no other than our ol 1 friend electricity, written with capital letters. Some well-known examples of electrical discharges taking place from portions of the earth's surface are adduced, and it is then naively assumed that such discharges of terrestrial electricity would produce the effect of an earthquake. The undulatory movements are supposed to be the result of a struggle of the electricity to break through cushions composed of soft, non-conducting materials, and the cracks and chasms opened in the soil to the power of the "electric jet" to rip asunder the surface.

The facts on which this extraordinary theory (or "conjecture," as the author very properly terms it) appears to be based are of two kinds. In the first place it is noticed that peculiar atmospheric and electrical disturbances have occurred at the same time as earthquazes. In the second place Dr. Schmidt is quoted to prove that the earthquake shocks which he had studied in Greece had very commonly a course from north-east to south-west. The author adds to this the fact that an earthquake-wave occurring in the United States in the year 1870 took the same direction. He then asks triumph intly, "Is not this the line of path habitually followed by electric currents?"

Excited beyond all bounds by this supposed discovery of the true cause of earthquakes, our author then proceeds to make a number of suggestions which are certainly rather sensational than practical. To the Society of Telegraphic Engincers he appeals to invent a conductor which shall ward off the electric currents and divert earthquakes from their habitual haunts. Medical men are requested to examine the bodies of people killed during earthquakes in order to discover "lightningscars." And lastly, Sir William Thomson and other eminent electricians are asked to "direct their attention to that storehouse of unlimited energy already filled within the bosom of the earth," and to utilise it for useful purposes.

This curious article may at least serve one useful purpose. Its author is evidently a man of some general knowledge and considerable culture, and the absurd errors into which he has fallen are manifestly the result 